\title{
Perceptions of Teachers and Learners about Factors that Facilitate Learners' Performance in Mathematics in South Africa
}

\author{
Avhasei Tsanwani, Ansie Harding, Johann Engelbrecht* and Kobus Maree \\ Dept. of Science, Mathematics and Technology Education, University of Pretoria, Pretoria, \\ South Africa \\ ${ }^{*}$ Corresponding author, email: johann.engelbrecht@up.ac.za
}

\begin{abstract}
Under-performance in mathematics is a challenge in South African schools. The purpose of this study is to advance views expressed by teachers and learners on factors that facilitate learners' performance in mathematics. The participants in this research were educators and learners from historically disadvantaged schools from similar socio-economic backgrounds in the Limpopo Province. Ten rural schools participated in the study, all government schools, with schools selected on the basis of their accessibility and performance. They represent both high-performing and low-performing schools in mathematics. Data were collected from learner focus group interviews and individual teacher interviews. Perceptions expressed by educators and learners from high-achieving schools and from low-achieving schools are juxtaposed and point to factors such as learners' and teachers' commitment and motivation, attitudes and self-concept, learners' career prospects, learners' perceptions of peers and teachers and teachers' perceptions of learners. These factors appear to influence disadvantaged learners' decisions to persist and achieve in mathematics despite their difficult circumstances.
\end{abstract}

Keywords: mathematics performance; learner perceptions; teacher perceptions; school effectiveness; South Africa

\section{Background}

The under-performance of learners in secondary school mathematics in South Africa is a concern to the whole country. In 2008 only $23.34 \%$ learners who sat for the mathematics senior certificate managed to achieve more than $50 \%$ (Department of Education, 2008). The situation has not improved-in 2012 only $22.68 \%$ learners achieved more than $50 \%$ for mathematics in the final grade 12 examination. The Trends in International Mathematics and Science Study is among the most comprehensive international studies that South Africa has ever participated in (Howie, 2003). This study shows that South African learners performed poorly in both mathematics and science. The situation is worst among African learners from rural areas (Kahn, 2001).

Even though mathematics education in South Africa is clearly not in a healthy state, there are indeed pockets of excellence. The scenario outlined above conceals, for example, the outstanding performances in mathematics of some historically disadvantaged schools of which one would not expect much in terms of success, given their impoverished environment. One example of such a success story is described by Zille (2011), who claims that many young people of average ability can become part of the 'story of success'. She describes how two learners from Masibambane High School in the poverty-stricken community of Bloekombos, both barely surviving in backyard shacks, came to be provincial top achievers, both in mathematics and in other subjects. Having investigated 
the reasons behind their exceptional performance, Zille concluded that the drive and impetus of the principal, Mr Naidoo, was paramount in this success story. She quotes Gladwell, who contends that exceptional success goes hand in hand with three factors: (a) opportunity; (b) natural ability combined with enormous personal effort; and (c) the proverbial 'hand of fate'-a confluence of circumstances that makes exceptional things possible. In the case of Masibambane High School the personal life of $\mathrm{Mr}$ Naidoo and his family triggered exceptional circumstances, which in turn provided opportunities to those learners who were willing to put in enormous personal effort.

In a supplement of the Sunday Times that highlights South Africa's top schools of 2008 (Sunday Times, 2009), the eighth position in the top 10 mathematics schools was, to the surprise of many, taken by Mbilwi High School, situated in the rural impoverished area of Thohoyandou in Limpopo Province. The school, with more than 2,000 learners, averages almost 60 learners per class. The school also took the top position in science in the country and the best 2012 grade 12 results in the Limpopo Province in mathematics and science (Zoutnet, 2013). The principal, a former pupil of the school, stated that the school was no different from other schools but had a 'secret menu' that made them high achievers: they worked as a family, with a great deal of attention given to pupils and advising them on their personal lives; they had 'team teaching' (more than one teacher teaches a subject, with different educators doing different papers); and they were united as staff.

Although there have been efforts within the school effectiveness research tradition based on Creemers's (1994) effectiveness model to pinpoint the determining factors for success in adverse circumstances, there is a need for investigation into this intriguing problem from a participant perspective. In this study we report on interviews conducted with teachers and learners from sample schools, both high-achieving and low-achieving and all from disadvantaged areas. The paper aims to give voices to teachers and learners in order to provide first-person views on factors determining success or failure in learner performance in mathematics. The paper does not propose to offer solutions for the underachievement problem; it rather aims to provide insight by focussing on perceptions of the people involved at grass root level.

\section{Review of Research on Factors Related to Mathematics Performance}

Researchers such as Attwood (2001) have suggested that achievement in mathematics in secondary schools is influenced by a variety of factors, including learners' abilities, attitudes and perceptions, family and socio-economic status, parent and peer influences, school-related variables such as a poor learning environment, learning culture, past racial discrimination and low expectations of principals and teachers. In a research project that included more than 8,000 pupils in 200 schools in South Africa, Howie (2003) found that the pupils' proficiency in English was a strong predictor of their success in mathematics in the Third International Mathematics and Science Study-Repeat. However, home language and class size were factors that were not found to have significant effect on their achievement, and socio-economic status had a lesser effect once certain class-level factors were taken into consideration.

Some studies have shown a correlation between a disadvantaged school environment and learners' poor achievement in mathematics. For example, learners in the Western and Northern Cape provinces in South Africa, which have mostly large white populations and well-endowed communities and schools, lead in grade 12 results, whereas those in Limpopo Province, with its largely African population, traditionally rank last in this regard (Van der Berg \& Burger, 2003).

Teachers' background and content knowledge contribute to poor performance, as has been shown by a number of researchers. Ogbonnaya and Osiki (2007) investigated the relationship between achievement in mathematics and teachers' background, teaching practices and professional development with grade 10 mathematics teachers in Lesotho. They found that teachers' background, such as qualifications, subject majors and experience, was a good predictor of students' achievement in mathematics. Similarly, Simkins, Rule and Bernstein (2007) emphasise the importance of improving the supply and quality of teachers teaching mathematics and science in South African schools in an attempt to improve learners' achievement in these two subjects. Furthermore, they underscore the 
importance of focussing on more schools (both high- and low-performing) instead of Dinaledi schools only in our attempts to deal with the challenge of inadequate achievement in the gateway subjects.

Al-Agili, Bin Mamat, Abdullah and Maad (2012), in their study on Libyan learners in primary and secondary schools, identified six factors that impact significantly on achievement in mathematics. Of these factors, teaching practices and methods had the highest impact and students' attitude towards mathematics the lowest impact. Other factors included teacher attributes, classroom climate and student anxiety. In a different study, also in Lesotho, Nenty (2010) reports that, while the gender of students had no significant influence on students' poor performance in mathematics, the person with whom the students were living, students' preferred occupation after school, the type of proprietor of the school and preferred classroom seating zone during mathematics lessons all had significant influence on performance.

Makgato (2007) conducted a study that is similar to ours. He focused on the learners' and educators' perceptions of why learners perform badly in grade 11 and 12 mathematics and physical science. He found that factors contributing to poor performance of learners in mathematics and physical science include the teacher's content knowledge and time management, parents' commitment to children's education, students' motivation and interest, and teaching strategies.

In a study in Nigeria, Jaiyeoba and Atanda (2011) investigated nine school quality factors that are likely to influence students' achievement in mathematics. Out of the nine variables, instructional materials and adequate toilet facilities were judged to have contributed significantly to students' achievement in mathematics. Mbugua, Kibet, Muthaa and Nkonke (2012) performed a study investigating the factors contributing to the poor performance in mathematics by form 3 students in secondary schools in Kenya. Factors contributing to poor performance included under-staffing, inadequate teaching/learning materials, lack of motivation and poor attitudes by both teachers and students.

Bloch (2009), Christie, Butler and Potterton (2007), Fleisch (2008), Kraak (2004) and Motala and Pampallis (2005) highlight the following major systemic problem areas affecting achievement in mathematics:

(1) decisions taken at a political level that have impacted negatively on education;

(2) the legacy of apartheid;

(3) increasing and endemic poverty levels in society in general but in the black population in particular;

(4) vast differences in the quality and quantity of teaching and learning taking place in private and former model $\mathrm{C}$ schools (section 21 schools) on the one hand and public schools (notably impoverished rural and township schools in particular) on the other;

(5) inadequate training of many teachers (underqualified teachers) in terms of both content knowledge (what to teach) and didactic knowledge (how to teach);

(6) poor management of many schools by headmasters (in collaboration with School Governing Bodies);

(7) poor infrastructure in many schools;

(8) insufficient time spent at schools (by both teachers and learners);

(9) failure on the part of the education departments (national, provincial, district) to support schools adequately.

In summary, common threads can be extracted from literature as to the factors impacting on poor mathematics performance. Circumstantial factors such as home environment, income and parental education play a role; teachers and their pedagogical as well as organisational approach have a strong influence; learners' attitude and work ethics have a definite impact. However, it should be emphasised that these claims are generalisations of complex situations and that unexpected success stories prevail in the direst of circumstances. In particular, these results fail to account for the success of some South African disadvantaged schools in spite of these background factors, as has been illustrated. 


\section{Novelty of our Study}

Maree, Mutshaeni, Engelbrecht and Sommerville (2011) conducted a study similar to ours to determine what influential factors caused the difference between the high-performing and the poorly performing schools in two districts in the Limpopo Province. They found that the main factors contributing to success included communication between all stakeholders involved, the quality of school management, and possibly the personality and style of school principals. They also found that parental involvement, whether voluntary or not, had a direct relationship to grade 12 results. That study corresponds closely to the study reported here. However, whereas the Maree et al. study explores quantitative relationships, our study uses a qualitative approach. Whereas factors influencing performance are reasonably well known from quantitative school effectiveness studies, the qualitative aspect together with the South African rural setting justifies and provides the novelty of our study.

\section{Theoretical Framework for the Study}

Given what has already been stated, we concur with the views expressed by Cho, Scherman and Gaigher (2012), who argue that it may be useful to assess effectiveness in science education by using the following lens to interpret data:

(1) focus on student characteristics (as possible enablers of success);

(2) focus on classroom characteristics (including instructional quality, teaching and classroom practice and physical resources);

(3) focus on school characteristics (including quality of curriculum management, professional teaching resources, school climate and physical resources);

(4) focus on context of schooling (national level; including a focus on policy matters and allocation of resources).

We believe that this lens provides us with a useful framework to address the goals of our study.

The purpose of the study, then, is to investigate aspects in learner contexts, classroom contexts and school contexts that may possibly influence performance in mathematics examinations. In contrast to most studies in the school-effectiveness tradition, this study focuses on participants' perceptions of factors influencing performance, rather than systemic factors that statistically seem to be significantly influencing performance.

\section{Methodology}

\section{Data Collection}

The study reported on here forms part of a bigger project that includes a quantitative comparison between high-performing schools and low-performing schools. In this paper we report on the qualitative part of the study only. For the purpose of this paper the term high-performing school (HPS) refers to schools that have attained a mathematics average of $60 \%$ and above for at least three successive years in the grade 12 final results, and low-performing schools (LPS) are those that have attained an average of $40 \%$ and below in mathematics for the same period. The data collection was based on three focus group interviews with learners from 10 schools as well as on individual interviews with four teachers. Interviews were conducted with four teachers in the four schools. Two of the teachers were from HPS and two from LPS from amongst the 10 schools in the sample.

Three focus group interviews were guided by one researcher. Interviews explored learners' experiences in the subject. Each focus group session lasted one to two hours. The first interview group consisted of seven learners (four from HPS and three from LPS), the second group of five learners (two from HPS and three from LPS) and the third group of six learners (three from HPS and three from LPS). Teachers were requested to select learners according to their performance in the grade 11 mathematics final examination. Where possible, one high-achieving learner with a mark of at least $75 \%$, one middle-achieving learner with a mark of between 40 and $60 \%$, and one low-achieving learner with a mark 
of at most $40 \%$ were selected per school. Where there were no high achieving learners in the schools chosen, all learners were correspondingly chosen on the basis of their examination ranking as compared with other learners in the class. Immediately after each focus group session, tapes were transcribed. Findings were summarised immediately after interviews so that one not only recorded the content of the group's discussion but also how each participant expressed him/herself (Simon, 1999). The focus group interviews proceeded according to guidelines by Simon (1999), in which there is an opening question, an introductory question, a transitional question, several key questions, an ending question and a final question. Among others the following key questions were used in the interviews:

- Could you describe the most important factors that enhance achievement in mathematics?

- What are the learners' challenges for success in mathematics?

- How do you know that a learner in your class will perform well in mathematics?

- Of all the factors raised, which are the most important ones?

\section{Data Analysis}

We collated perceptions expressed in both the focus group interviews and teacher interviews, grouping comments under three headings and distinguishing between responses from HPS and LPS. We believe that the methodology of contrasting data from HPS and LPS allows different perceptions in HPSs and LPSs to be brought out. That said, we realise that the data collection methods using mixed groups (HPS and LPS) is unusual. However, we chose this strategy as a method to deepen discussions within the interview groups.

Data triangulation (the collection of data from multiple sources with the intention of obtaining diverse views on the phenomenon being studied for validation purposes) was used. Data sources for the focus groups comprised grade 12 learners whereas interview data were obtained from teachers from wellperforming schools and underperforming schools in mathematics.

\section{Ethical Considerations}

Written permission to conduct research in Vhembe district was sought and obtained from the Regional Director. Permission for learners to participate was obtained from the school principals, respective mathematics teachers and learners or learners' parents. The aims and objectives of the study were explained verbally to the learners by the researcher prior to their participation. Assurance was given that no person or school would be identified.

\section{Results}

\section{Teachers' and Learners' Perceptions on Performance Expectations}

\section{Low-performing schools.}

Although teachers in LPS suggested various factors that facilitate achievement in mathematics, the most frequently mentioned factors are related to learner's behaviour or background. These characteristics are perceived as unalterable and such a perception leads to low expectations of the performance level of their learners. For instance, one teacher felt that learners did not always see the necessity for attending class regularly because 'most of them have already lost hope in mathematics'.

Another teacher stated that the level of the learners' understanding of mathematics was not always what she would like and that most of the learners were limited in their aptitude for learning the subject:

I think most of the learners are just forced to do mathematics by their parents or friends. They just can't do it.

Learners from LPS schools also referred to the low expectations of their peers as a factor in discouraging their own learning. One LPS learner stated:

Most of the learners here at our school have told themselves that mathematics is difficult. When we write a test we know that many of us are going to get zeroes and most of us do not practise anymore. They are 
discouraged even when the lesson is on, you may find that some are asleep, not listening at all. They are the learners who spread bad news that mathematics is difficult an no matter what you do you will not pass it.

Learners in this group acknowledged that their mathematics background was poor because their teachers in lower grades were 'not active enough', meaning that these teachers did not give them enough tests, homework and class work or did not correct it. The teacher's strict guidance in the practice of problem solving was seen as a first step towards independent success in mathematics:

I think a teacher must give his/her learners more work so that they can work hard by themselves and not the teacher doing everything for them.

However, most learners in this group admitted that they were not self-disciplined enough. Some of them, when given some work to do, would simply not do it and others just copied from their classmates. Some learners agreed that they did not practise mathematics enough, attended classes late, and did not even consult their teachers when they did not understand some topics.

Most of us learners are lazy. Because when we are given the work like today, arriving home we just put it aside and do not look at it. We are very fond of bunking the work. You only look at it when there is an announcement of a test.

At the same time, many learners said that there were no proper learning facilities at home where they could learn effectively. Many of them did not give themselves enough time to practise mathematics because of the lack of time management. They did not know how to stop their friends from visiting them when they were studying.

Apart from the perceptions above, the comments from learners from LPS focused mainly on the teachers' behaviour, and are indicative of the influence of teachers' attitudes on performance. In LPS some teachers reportedly discourage learners from taking mathematics that will provide for university entrance but rather encourage them to settle for a lower level of mathematics. Learners note that such low expectations compromise their chances of acceptance into mathematics-related careers at universities.

Learners from LPS were of the opinion that some teachers do not enjoy teaching mathematics, and as a result their attitudes are negative both towards the subject and towards the learners whom they teach. These attitudes do not improve teacher-learner communication and are considered to form a barrier to proper learning of mathematics.

Furthermore, learners in this group were critical towards teachers and boldly stated that many teachers did not know how to teach properly. Some of the mathematics topics, they claimed, were not discussed at all.

There are those teachers who do not teach some of the topics, and they will tell you that you will be taught such topics in winter or Saturday schools. In our school linear programming was not taught in grade 11.

Learners also commented that they sometimes felt humiliated and degraded by their mathematics teachers, some of whom 'treat us like small children'. Some teachers were seen as unapproachable, while others were not available for consultation. Learners felt that they could not ask questions in the class because they would be ridiculed.

I think everyone is afraid of her (teacher). When you ask a question you get a very negative response. You get the impression that you are bothering her. When you approach her you must be ready for anything.

\section{High-performing schools.}

Teachers from HPS convey high expectations of learners backed up by support services, offering a positive learning experience. On a different level, on the question of how to motivate learners in 
mathematics, one teacher stated that one of the factors that contribute to his learners' good performance is motivating them through career choices in mathematics to expect more of themselves. He stated that:

Most of our learners in Grade 12 do not know what they want to do after grade twelve. The year I took my learners on a trip to Gauteng to visit science laboratories and some other companies, our results improved in mathematics and physical science. When we came back from the trip everyone was encouraged to work very hard, because they were shown the importance of studying mathematics in high school.

One teacher from a HPS encouraged his learners to associate with other successful and serious learners in their class.

When you associate yourself with failures you are likely to fail. So for my learners to succeed they must associate themselves with learners who are serious about mathematics.

Learners from HPS received, and in most cases seemed to have internalised, the message from their teachers that mathematical success leads to university admission in mathematics and sciences and improved the possibility of obtaining a bursary.

My teacher wants us to do well in mathematics. He always says that we have to do well in mathematics to make it in the world and to get a good job.

A learner from an HPS who regularly stayed after school to practise mathematics with her classmates stated her belief that all learners can succeed.

Many learners asserted that mathematics career options influenced them to put more effort into their studies. For example learners discussed how important it was to know the career you wanted to pursue as strategy for success in mathematics achievement:

I have started thinking about what I would like to do in Grade 10, I have already set my mind on what I would

like to do and this has helped me to work very hard in mathematics. In fact, I am good in mathematics.

Learners were influenced by peers who often talked about going to university so they could fulfil their dreams of becoming an engineer or going into medical school. Another learner described how he obtained information from his cousin who was working as an electrical engineer and he was influenced to follow the same career.

In general, learners from HPS expressed positive perceptions about their teachers and peers. The majority of the learners interviewed felt that they were expected to work hard, that they tried hard to get good grades in tests, respect their teachers and have a good self-image, and that it was important to do well in mathematics. In stark contrast, teachers and learners from LPS were negative and tried to put the blame on the other parties involved.

\section{On Work Ethics and Practices}

\section{Low-performing schools}

Learners from LPS frequently reported doing only what is required, such as doing only the compulsory exercise questions. For the most part problems in the textbooks were referenced solely in connection with similar previous examination questions.

Many learners also felt that their teachers concentrated only on those learners who were performing well and that some learners did not get proper attention. Most of the class and homework assignments were marked by their fellow classmates. This practice was seen by most learners as unfair.

I think what makes learners learn better is when the teachers themselves correct the learners' work, not giving the work to our classmates. If that is done the teacher will have an opportunity to revise the section that is not well understood so that we can work on it again. 
An LPS teacher argued that one of the factors that made learners perform well in mathematics was for them to respect and manage time profitably in learning the subject. She described this in the following way:

I believe in time and time only. I normally tell my learners that it is not that mathematics is a subject which requires more time, because if you offer it enough time, it will be very simple. They need to practise regularly and give this subject time and avoid bad social behaviours.

Learners from poorly performing schools pointed at teachers' work ethic, claiming that some teachers skipped classes without any apparent reason and saw this practice as 'a lack of motivation from the teacher and not studying [preparing] well', which could contribute to their failure.

\section{High-performing schools}

Teachers of HPS organised special classes for under-performing learners following learner assessment. In this regard a teacher remarked:

The Grade 12 syllabuses in our school end before June for all subjects. Our principal is very strict on that; you will feel ashamed if you do not finish the syllabus in time because you will be the only one left. The reason is that before the final examination our learners must write at least four exams with questions taken mostly from previous examination question papers, and learners who do not perform well are given thorough practice again.

According to another HPS teacher, all papers were supposed to resemble the final examination standard. He often put more emphasis on the thinking behind the answer rather than on the answer itself. His learners were often asked to explain their solutions to other learners. Similarly, a colleague saw learners' success in the purpose of mathematics learning, pointing out that it is important to teach learners application topics in mathematics. He indicated that mathematics learning is more meaningful when it is related to real life application:

I think problem-solving is one of the main reasons why we teach mathematics. We do not teach mathematics so that learners can understand how to find the derivative of a function only. We teach them skills so that they can be able to solve real world problems that relate to the mathematics in class. They must be able to find the maximum and minimum values using calculus. Application of mathematics to real world problems is very important.

One participating teacher listed a manageable teaching load as one of the factors facilitating learners' success in mathematics, since it provides professional commitment. He explained:

When I started teaching at this school I was the only teacher who was teaching mathematics in the whole school and I was not teaching mathematics only, I had to teach biology and physical science as well, which was discouraging. But now things have changed. I am concentrating on mathematics only and this has given me an opportunity to further my studies in mathematics at Wits University.

Learners in this group were always working together with other learners in their class, preferring those who were motivated to do well in mathematics. These learners played an important role and were available even when normal teaching was over and they never missed mathematics classes. As a learner said:

I think this is the subject that requires someone to give himself more time to study and serious dedication. Not only relying on the teacher to give you information, because the teacher cannot do everything for you, teachers also have their own personal issues to deal with.

Learners from HPS tended to spend considerably more time on challenging exercises and concepts that required well-developed skills. 
You must spend less time on the chapters that you already know and spend a lot of time with those that you do not understand well. If they are difficult for you, you must go to the teacher or a fellow classmate and ask him, but mostly to your classmate because if the teacher gives you the correct answer, you will think it is obvious because she is a teacher but if it is your fellow classmate you will tell yourself that if she can do it so can I.

Many learners from HPS mentioned the value of working with peers to perform well in mathematics.

We used to practise with our classmates, mostly those who were serious in the subject. Our teacher would encourage us to make some groups. Group discussions were done especially when we were practising previous years' question papers. In our case we were having our own group which was from the previous year and it was not formed by the teacher, we just grouped ourselves.

Although some learners were critical of their teacher's mastery of some topics, they respected their teachers.

If I were to be asked to give advice to any learner, I can encourage a person to love the teacher who teaches him. It is difficult to be successful if you do not love and respect your teacher.

Learners in this group also recognised that their teachers wanted them to succeed in mathematics. These teachers were willing to stay longer with learners who were struggling to find the correct solutions. In this regard the positive effort from teachers who encouraged their learners to do their best academically is illustrated by this comment:

In our school there was a time when our teacher used to keep some of us longer until we get the given exercises right and we had to get those exercises correctly. In fact most of those exercises were similar to the ones from previous examination papers. You have to get those exercises right because you will only get out of the classroom after completing the correct answer. It was like a punishment but it helped.

Most learners of HPS considered learners' characteristics such as good work ethics, peer encouragement and discipline as factors contributing to good performance in mathematics. They were willing to work hard and found pleasure in doing so. In contrast, many learners from LPS were unhappy and try to put the blame elsewhere- -they claimed they did not get the attention they deserved, and that there were too many changes of teachers.

\section{On Motivation and a Culture of Learning}

Low-performing schools

One teacher from LPS emphasised the need for extrinsic motivation of learners:

but here at our school only bright learners ask to be taught extra classes, the rest come because I threaten to punish them, and still not all of them are motivated to come. The lazy learners are a problem at this school.

Another teacher was not interested in becoming a teacher, let alone a mathematics teacher:

The event that led me to become a mathematics teacher was mainly that my guardians wanted me to be a teacher whereas I wanted to work in a bank. I was dependent on them financially so I didn't have any alternative. Teaching was not my choice. Sometimes due to some de-motivation from the government I feel like quitting.

A teacher's lack of interest in the subject may rapidly result in learner apathy and this affects performance levels, according to another teacher: 
In our school we have a shortage of qualified mathematics teachers. As a result even people who had mathematics up to Grade 12 are forced to teach mathematics in lower grades. These teachers have no interest in the subject in the first place and this is transferred to the learners ultimately.

Indeed, several LPS learners reported on their demotivation to attend mathematics classes. These learners stated that the reasons for demotivation were poor instructional methods and perceived lack of supportiveness of the teachers. The comments of learners described and explained how their teachers encouraged or discouraged learning through instructional methods:

I think the teacher must do a lot of follow up to the learners because she may think that all the rules have been understood by all learners whereas the majority of the learners haven't. The teacher should make sure that all learners understand the basics.

The impression is that learners in this group, generally speaking, were not well motivated. Some said that they were bored with what they were learning and others remarked that they would not pass because the subject was difficult. It was felt by some learners that teachers did not always create the right climate in the classroom, one that was conducive to raising learners' motivational levels.

\section{High-performing schools}

Upon reflection on reasons for the school's success a teacher mentioned learners' background and a culture of learning:

Most of the learners here have a good background in mathematics, and some are very intelligent. If you just come without being prepared you will be in for a great shock. They prepare themselves before coming to the class. In this school there is a culture of learners willing to learn on their own.

Another teacher was encouraged by his secondary school mathematics teacher once the teacher noted his interest. He subsequently elaborated on some challenges in teaching mathematics in his classes, such as the attitudes of his learners towards the subject and how he tried to overcome these:

There are so many challenges in teaching mathematics today. Many learners come to school with the attitude that mathematics is a very difficult subject, so I have to eradicate that from their minds, and in turn I become motivated to continue teaching as I see some of these learners succeeding. Also I have to show learners that I can teach this subject, which many people think is a hard subject.

Another teacher contended that learners knew his family background because he came from the same local area. He suggested that a positive role model is key to success. In order to motivate his learners to succeed in mathematics, this teacher stated that he invited people from outside to come and motivate his learners:

In most cases we invite people from different companies to come and explain to the learners how mathematics is applied ... like now we are living in the time of technology, which needs mathematics learners. So when I invite these people they come and motivate them and show them that if you are good in mathematics and obtain good symbols we can absorb you here and there.

Despite another teacher's belief that one of the most important factors that contributed to his learners' good performance in mathematics was interacting with other learners, he also advocated that there must be competition between learners:

I believe learners must be able to work together and give assistance to one another. They must be able to create a sort of competition among themselves. Not a destructive competition, I mean, a competition to motivate each other as friends. 
It was clear from the discussions that intrinsic motivation to achieve in mathematics was also a significant factor for the success of learners from this group. As two HPS learners stated:

One thing that motivates me is that math is interesting. I want to do something that is not common, something that other people are afraid of, something unique which is not done by many people, approaching life differently.

I think this is the subject that requires someone to give himself more time to study and serious dedication. Not only relying on the teacher to give you information, because the teacher cannot do everything for you, teachers also have their own personal issues to deal with.

Self-motivation was clearly the item considered most likely to influence success by both learners from high-achieving schools. In summary, whereas extrinsic motivation was perceived as a strong motivating aspect, intrinsic motivation was the item considered most likely to influence success by learners from HPS. Learners' motivation was largely directed towards performance goals, such as homework completion, examination and test success.

\section{Discussion and Conclusions}

It should be reiterated that this study (which was based on a qualitative approach) was not intended to be a classic school effectiveness study. Firstly, school effectiveness studies mostly employ a quantitative analysis method. Secondly, learner and teacher perception studies (such as this one) de-emphasise school or systemic factors that seem to be influencing performance statistically significantly.

This study provides insight into the interrelated issues that contribute to the unexpected success of learners from high-performing but disadvantaged schools. By listening to learners and teachers, a better understanding was gained of this phenomenon and various factors were identified that separate HPS and LPS. Learners from HPS accord more weight to factors directly within their control, such as class attendance, active participation and homework completion. On the other hand, learners from LPS place more emphasis on teachers' characteristics and behaviour. They feel unappreciated by their teachers in terms of efforts they put into their school work and they experience no drive for hard work because they feel they are not treated with respect. These results support the findings by other researchers (Al-Agili et al., 2012; Makgato, 2007; Ogbonnaya \& Osiki, 2007). Learners from HPS share common characteristics, such as being very positive about themselves and their ability to do mathematics, being well motivated and knowing what they want to do after grade 12 .

The final conclusion is that there are no mysterious factors that lie at the root of the differences between HPS and LPS learner achievement in mathematics. The application of sound teaching and learning principles fosters an environment where pupils are motivated to reach their full potential. The findings are important for the South African education system because changing school climate and improving the learning strategies in mathematics are much easier to achieve than changing background factors affecting learners' performance.

\section{Acknowledgements}

The financial assistance of the National Research Foundation towards this research is acknowledged. Opinions expressed and conclusions drawn are those of the authors and cannot necessarily be attributed to the supporting organisation.

\section{References}

Al-Agili, M., Mamat, M., Abdullah, L., \& Maad, H. (2012). The factors influencing students' achievement in mathematics: A cakse for Libyan students. World Applied Sciences Journal, 17(9), 1224-1230.

Attwood, N. (2001). Relationships between mathematics aggregate, socio-economic status and gender of grade 8 learners in a school situated in an economically depressed area of the Cape Flats. Pythagoras, 55, 42-48.

Bloch, B. (2009). The toxic mix: What's wrong with South Africa's schools and how to fix it. Cape Town: Tafelberg. 
Cho, M.-O., Scherman, V., \& Gaigher, E. (2012). Development of a model of effectiveness in science education to explore differential science performance: A case of South Africa. African Journal of Research in MST Education, 16(2), 158-175.

Christie, P., Butler, D., \& Potterton, M. (2007). Report to the minister of education. Ministerial Committee: Schools that work. Retrieved on the July 19, 2013, from http://www.sbmmetsouth.co.za/Schools_that_work_ministerial_ committee_report.pdf

Creemers, B. (1994). The effective classroom. London: Cassell.

Department of Education (2008). Abridged report: 2008 National Senior Certificate Examination results. Pretoria: National Department of Education.

Fleisch, B. (2008). Primary education in crisis: Why South African schoolchildren under achieve in reading and mathematics. Cape Town: Juta.

Howie, S. J. (2003). Language and other background factors affecting secondary pupils' performance in Mathematics in South Africa. African Journal of Research in MST Education, 7, 1-20.

Jaiyeoba, A. O., \& Atanda, A. I. (2011). School quality factors and secondary school students' achievement in mathematics in South-Western and North-Central Nigeria. The African Symposium, 11(1), 91-100.

Kahn, M. J. (2001). Changing science and mathematics achievement: Reflection on policy and planning. Perspectives in Education, 19(3), 169-176.

Kraak, A. (2004). An overview of South African human resources development. Cape Town: HSRC.

Makgato, M. (2007). Factors associated with poor performance of learners in mathematics and physical science in secondary schools in Soshanguve, South Africa. Africa Education Review, 4(1), 89-103.

Maree, J. G., Mutshaeni, H. N., Engelbrecht, J. C., \& Sommerville, J. (2011). An analysis of factors influencing Grade 12 results. Journal of Educational Studies, 10(1), 130-152.

Mbugua, Z. K., Kibet, K., Muthaa, G. M., \& Nkonke, G. R. (2012). Factors contributing to students' poor performance in mathematics at Kenya certificate of secondary education in Kenya: A case of Baringo county, Kenya. American International Journal of Contemporary Research, 2(6), 87-91.

Motala, S., \& Pampallis, J. (2005). Governance and finance in SA schooling in the first decade of democracy. Johannesburg: Centre for Education Policy Development.

Nenty, H. J. (2010). Analysis of some factors that influence causal attribution of mathematics performance among secondary school Students in Lesotho. Journal of Social Science, 22(2), 93-99.

Ogbonnaya, U. I., \& Osiki, J. O. (2007). The impact of teacher qualification and subject major in the teaching of mathematics in Lesotho. African Journal of Cross-cultural Psychology and Sport Facilitation, 9, 37-48.

Simkins, C., Rule, S., \& Bernstein, A. (2007). Doubling for Growth: Addressing the maths and science challenge in South Africa's schools. Retrieved July 19, 2013 from http://dspace.cigilibrary.org/jspui/handle/123456789/24944

Simon, J. S. (1999). Conducting successful focus groups. Saint Paul, MN: Amhest H. Wilder Foundation.

Sunday Times (2009, October 18). SA's top schools. Sunday Times, 1.

Van der Berg, S., \& Burger, R. (2003). Education and socio-economic differentials: A study of school performance in the Western Cape. South African Journal of Economics, 71(3), 496-522.

Zille, H. (2011). Outliers-The story of Masibambane High School. Retrieved February 19, 2011 from http://www. moneyweb.co.za/mw/view/mw/en/page295025?oid=525768\&sn=2009+Detail\&pid=66362

Zoutnet (2013). Mbilwi does it again! Retrieved June 19, 2013 from http://www.zoutnet.co.za/details/14-01-2013/ mbilwi_does_it_again/16879 